SCHOLARS: Journal of Arts \& Humanities Print ISSN: 2773-7829; e-ISSN: 2773-7837

eJournal Site: www.cdetu.edu.np/ejournal/

- Peer-Reviewed, Open Access Journal

- Indexed in NepJOL; Star-Ranked in JPPS

- Permanently Archived in Portico

\title{
The Op-ed Articles on the Millennium Challenge Corporation (MCC) Project: A Rhetorical Analysis
}

\author{
Biranchi Poudyal \\ Independent Researcher, Bhadrabas-3, Kathmandu, Nepal \\ Corresponding Author: Biranchi Poudyal, Email: biranchipoudyal@gmail.com
}

\begin{abstract}
This paper attempts to make a rhetorical analysis of six op-ed articles on the Millennium Challenge Corporation (MCC) project, which are published online in the English daily newspapers of Nepal. This study has discussed how the authors in each article have used the language and context as a medium to persuade the readers in favour or against the MCC project and also to identify the rhetorical techniques that are used to accomplish their purpose. The rhetorical analysis is supported by the theoretical ideas of Aristotle and Kenneth Burke. In particular, Burke's concept of dramatism pentad has been used to find the answer of what was done (act), when or where it was done (scene), who did it (agent), how he did it (agency) and why (purpose). The findings of the study show that these authors have used effective rhetorical techniques to present the same situation in different ways, using their percussive appeals in their writing and the motive to bring the readers under their rhetorical influence. This study further reveals that the authors have used logos (logical reasoning) as the major tool to support the MCC project and have mainly used the scene-purpose ratio as a rhetorical tool to push the anti-MCC ideas. Finally, the study concludes that tracing out the relationship between the pentadic elements helps the critical readers to find the specific motives of the authors and also identify the rhetorical techniques used in their writing.

Keywords: MCC, persuasion, pentad, motive, scene-purpose ratio, new rhetoric
\end{abstract}

\section{Introduction}

The op-ed articles, in full form 'opinions and editorials,' published in the newspapers are usually a rich source for rhetorical analysis as they are often related to a particular event or happening. This paper attempts to explore the use of language and motives in op-ed articles about the Millennium Challenge Corporation (MCC) project published in various English newspapers of Nepal. They include The Kathmandu Post, The Rising Nepal and My Republica. The articles were chosen, which were published from November 2019 to April 2020. To be more precise, this paper focuses on how these

Article History: Submitted 24 October 2021 Revised 10 January 2022 Accepted 23 January 2022

\section{Copyright Information:}

Copyright 2022 (c) The Author(s). The publisher may reuse published articles with prior permission of the concerned author(s). The work is licensed under a Creative Commons Attibution 4.0 International License (CC BY 4.0).

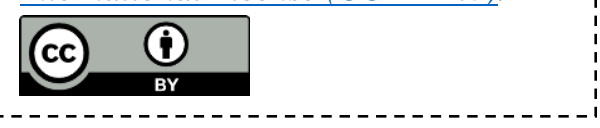

Volume 4, No. 1, February 2022 [pp. 53-64]

SCHOLARS: Journal of Arts \& Humanities 


\section{The Op-ed Articles on the Millennium Challenge Corporation (MCC) Project 54}

authors have used the language as a medium to persuade the readers either to support or oppose the MCC project. In addition, it also examines the motives of each op-ed article in relation to the step of the Nepal Government regarding the MCC project. In this regard, Denis McQuail states, "since the early 1970's, the belief that mass communication is a powerful force which has gained strength, in part from studies that document a correspondence between the amounts of media attention an issue receives and the amount of public concern about the problem" (23). Today, the newspapers not only give information, but also they influence the opinion of the people and the pattern of influence executed through the use of language, which can be traced through a rhetorical analysis of any newspaper article.

The op-ed articles published in the widely circulating newspapers function as a vibrant tool to proliferate different social, political and economic issues as proposed by the respective authors. While making a critical reading of the op-ed articles, one can find such rhetorical devices and methods employed within the article that are directed to inject certain viewpoints of the readers. The rhetorical analysis gives a broad insight to discover the hidden motives for writing such articles. With the ability to make rhetorical analysis, the readers can identify the issues raised by the authors and opinions embedded in the text through manipulation of language.

For a rhetorical analysis of op-ed articles, this paper has used the theoretical ideas of Aristotle's 'modes for persuasion,' also known as rhetorical appeals, and Kenneth Burke's concept of dramatism pentad. In line with their ideas, all the selected op-ed articles about the MCC project directly or indirectly support or oppose the endorsement of the MCC project. They have used different modes of persuasion and are loaded with various motives. Thus, the major objective of the paper is to find out various modes of persuasion that are embedded in the op-ed articles and to analyze the motives behind making a particular argument in them. This paper has raised two research questions: firstly, how are Aristotle's rhetorical appeals, ethos, logos and pathos used in the op-ed pieces? Secondly, what is the motive of the authors in making a particular argument in the op-ed articles? This paper assumes that the rhetorical appeals are implicitly visible in various forms of logical, ethical and emotional arguments made by the authors. Furthermore, the motives behind certain arguments can be identified after analyzing the answer of who, what, when, where, why and how in the op-ed articles.

On 1 June 2019, the United States Department of Defence unveiled the IndoPacific strategy report in which Nepal, along with Sri Lanka, has been added to the United States (US) Government's 'State Partnership Programme' with the Indo-Pacific partners (Bhatta). The document entitled 'Indo-Pacific Strategy Report: Preparedness, Partnership, and Promoting a Networked Region' suggests that the countries included in the document are counted as fundamental parts of the strategy. Following the same event, the controversies surrounding the MCC project gained the maximum media coverage in Nepal that focused on different views regarding the project. Some political leaders from Nepal, like Bhim Rawal and Dev Gurung, are constantly pointing out the flaws of the project. At the same time, the op-ed articles published in the newspapers have always favoured it by ignoring the flaws pointed out by the leaders. On the one hand, many op-ed articles are more tilted to persuade the people about the positive sides of the project. However, it has not made any attempt to address the drawbacks of the project, as pointed out by the political leaders. In addition, some articles also pointed out the drawbacks of the project, ignoring and discussing its possible benefits for Nepal. Thus, both are biased in their own terms of making their claims. 
The Op-ed Articles on the Millennium Challenge Corporation (MCC) Project 55

\section{Rhetorical Analysis: The Ideas of Aristotle and Kenneth Burke}

Rhetoric is defined as "the faculty of discovering in the particular case, what the available means of persuasion are" (Aristotle 2). The critical readers always try to identify the distinct kind of stylistic choice made by the authors that actually fulfils their motive of making an argument for exerting an influence in the readers. The study of rhetoric, when applied to a specific area such as newspaper articles, opens the ground for recognizing and differentiating various stylistic options that are embedded in the text. Rhetoric is sometimes equated with the idea of discourse and often understood as a form of ideology presented in a specific context. It is, however, distinguished by its focus on persuasion and can be further explored in terms of the notion of motive embedded in the rhetoric (McNally 114). Similarly, talking about the concept of dramatism and rhetoric, Burke in his book A Grammar of Motives (1945) has explained the dramatistic pentad as the rhetorical elements that are important for determining the motivation of characters in a play: act, scene, agent, agency and purpose, which are often known as a set of five elements (2). Burke identified a method of analyzing the semantic dimensions of language through a five-part dramatism pentad that describes the living stories. He has mentioned that the words are chosen "because of their dramatic potential and that we each have a preference for particular parts of the pentad" (132). He also noted how "you can understand a story or speech by identifying how pairs interrelate, such as the sceneact ratio of Hamlet" (132). The foundation of dramatism is the concept of motive: the reasons why people do the things they do. Burke set up a "pentad," which has five questions to identify the motive and the questions that are somehow similar to six 'Wh' questions often used by the news reporters such as who, what, when, where, why and how (12).

As per Burke's interpretation, the context remains important while studying the motive of any action and every part of pentad is equally significant to get the overall analysis. To put it simply, the op-ed articles about the MCC project published in the newspapers are to be studied along with the context when they were published; who wrote these articles via what means and the combination of all answers lead to the motive of writing these articles. According to David Blakesley, Burke himself has used the pentad on many kinds of discourse, especially poetry and philosophy. He also later added a sixth term 'attitude,' making the pentad into a hexad. Whether it is pentad or hexad, the point is that 'well-rounded statements' about human motivation will make a reference to act, scene, agent, agency, purpose and attitude (Nordiques 2). He further added that Burke intended the pentad to be a form of rhetorical analysis that the readers can use to identify the rhetorical nature of any text, group of texts, statements, explaining, or representing human motivation. It is Burke's point that any 'well-rounded' account of human action must include a reference to the five (or six) elements of the pentad.

There are many previous works in academia that used a pentad method to analyze Obama's rhetoric. For instance, Liu Xiaoyan and Nancy Lynch Street analyze the pentadic ratios of Obama's "A Perfect Union" speech on the issues of race to discover the political motive of the piece. Given that Obama's rhetoric has previously been explored by looking at his narratives through Burke's dramatistic pentad, which is useful to explore President Obama's farewell address to continue to grow and develop this emerging line of scholarship. In his farewell speech, he crafted a chronological story about America, his own life and legacy, and the responsibility of US citizens, applying pentadic criticism to these stories illustrates the perceived motives for Obama's telling of them. There are numerous studies that the scholars have embraced Burke's method of pentadic criticism to better understand a broad range of rhetoric. For instance, the pentad 


\section{The Op-ed Articles on the Millennium Challenge Corporation (MCC) Project 56}

has been used to explore various American political speeches, religious rhetoric and popular media. Additionally, the scholars have used Burke's pentad as a method to analyze the presidential addresses.

Sam Leith, in his book entitled Words Like Loaded Pistols: Rhetoric from Aristotle to Obama, has argued that ethos is about establishing an authority to speak on the subject; logos is logical argument for a point; and pathos is an attempt to sway an audience emotionally. Leith has purposed an example to summarize what the three look like:

Ethos: 'Buy my old car because I'm Tom Magliozzi.' Logos: 'Buy my old car because yours is broken and mine is the only one on sale.' Pathos: 'Buy my old car or this cute little kitten, afflicted with a rare degenerative disease, will expire in agony, for my car is the last asset I have in the world, and I am selling it to pay for kitty's medical treatment. (17)

Following the example of Leith, the ethos, pathos and logos are the modes of persuasion used to convince the audience and are all represented by Greek words. These are also known as three artistic proofs, which are the terms coined by Aristotle. Firstly, the ethos or the ethical appeal simply means to convince the audience by using the author's credibility and character. It also involves the choice of appropriate language to sound fair and unbiased while speaking or writing. So, it can be said that even the expertise, achievement or social position of the author or speaker helps in strengthening the appeal of ethos.

Burke has called the humans as the symbol, using animals and in his long career, exploring how the humans communicate; he has invented a variety of systems for analyzing speech and writing. His pentad can be explained by describing the value of each question and the way it helps to identify the motives in any discourse. Firstly, there is an act, which deals with the questions like: What happened? What is the action? What is going on? What action? What thoughts? The act refers to "motivated and purposeful action either in deed or discourse, which provide the ground for identifying the meaning of action" (Kneupper 305). Secondly, there is a scene, which deals with the questions like: Where is the act happening? What is the background situation? The scene is a 'container,' the place where the action of the act occurs that may include a physical location and a contextual situation, occasion, event and time. Thirdly, there is an agent, which deals with the questions like: Who is involved in the action? What are their roles? The agent is a person or group of people who performs in the act or who enacts the meaning in any discourse. Fourthly, there is an agency, which deals with the questions like: How do the agents act? By what means do they act? The agency is a technique or method by which the agent achieves his or her goals. Lastly, there is a purpose, which deals with the questions like: Why do the agents act? What do they want? The purpose is the reason that the agent acts and the outcome that they are seeking from what they do. While analyzing the specific acts or scenes, it can obviously lead the readers to some understanding about what motivated someone to do something. What really makes Burke's pentad useful is his emphasis on the relationships among the terms. He is particularly interested in the relationships or ratios between the terms. For example, by analyzing the "act-to-scene ratio," the facts about how a scene, or social context can be achieved, which influences the act. The pentad is especially useful while analyzing the point of persuasion in writing. How does the author define the act? If the author is emphasizing the agent, what happens if you look at it from the point of view of the scene? If the author is emphasizing a tool such as some kinds of new technology (agency), what if someone emphasizes the purpose? The pentad is a way of shifting perspectives that just might lead to some winning arguments. 
The Op-ed Articles on the Millennium Challenge Corporation (MCC) Project 57

Apart from the modes of persuasion and dramatic pentad, there are other theoretical lenses like the new rhetoric to analyze the discourse in the op-ed articles. The new rhetoric framework begins from the audience whom they define as "the ensemble of those whom the speaker wishes to influence by his argumentation" (19). The audiences are vital in the new rhetoric because a rhetor adopts his or her values and judgments in the light of the audience he or she addresses. The new rhetoric is a result of various efforts of bringing back rhetoric from the marginal status. The field emerged after the work of Chaïm Perelman and Lucie Olbrechts-Tyteca in their book The New Rhetoric (1969), but both the notion and the idea for the need of 'new' rhetoric, which is different from the 'old' can be traced to the works of Burke's A Rhetoric of Motives (1950) and Rhetoric - Old and New (1967).

\section{Rhetorical Analysis of the Op-ed Articles}

This paper has made the rhetorical analysis of the selected op-ed articles to find out the motive of each. The article entitled "Debunking the Nonsense on MCC" by Prashaant Singh, published in My Republica, has tried to clarify the misconception and false narrative regarding the MCC project. The article has explicitly supported the project by giving a logical reasoning. The author of the article has used logos as the mode of persuasion, giving clarifications for each negative narrative. The author has coherently organized the reasoning in every paragraph as arguing, "The first nonsense invented by our political spin-doctors is, second nonsense being spread is that MCC projects are, third and probably most provocative nonsense being manufactured is, fourth nonsense doing the rounds is that MCC is" (4). In this way, the author has given a reason for every argument and logical appeal that is done to persuade the readers to support the project. Besides the logical reasoning, the aspect of ethos is also visible in the credibility of the author as he is the secretary of Samaajwaadi Party. His position as a political figure has a lot of influences among the public and his discourse in such political issue is likely to be believed by many people. Similarly, while analyzing the motive of this article on the basis of Burke's pentad theory, it is argued that this particular article has the scene-purpose ratio. While talking about the context of this article, it was written when the government indicated that the MCC project would be ratified through the parliament despite its reservations from some of the ruling party leaders. As the then KP Sharma Oli administration was preparing to ratify the US programme, some members of the ruling party continued to express deep reservations, arguing the grant as part of a larger strategy to counter the country's northern neighbour. In response to the same context, this article was written to challenge all the claims made against the project. It has explained every controversial claim in separate points. So, the primary purpose of this article is to install a positive viewpoint about the project by clearing all the controversies and negative claims. The purpose of advocating the positive side of the project automatically indicates the fact that this article is favour of the project.

Another op-ed article entitled "A Model for Transparent Development Projects" by Troy Kofroth who is the MCC's resident country director for Nepal has detailed all the goods of the project for Nepal and has further validated his arguments by focusing on the history of Nepal-US diplomatic ties. While going through the article and analyzing it in terms of Burke's pentad, there is an agent-agency ratio in the opinion. Firstly, talking about the agent, it is written by an American citizen who is also the MCC's resident country director for Nepal with responsibility to pass the national contract at any cost. The author has used The Kathmandu Post not just as a platform to express his views, but he has given his arguments in support of the project. It is very 


\section{The Op-ed Articles on the Millennium Challenge Corporation (MCC) Project 58}

clear that this media platform is used more as an agent to reach the mass with his rhetorical voice. Here, both the agent and agency are engaged in making the opinion that directly or indirectly motivated them to narrate good things about the project. Thus, the motive behind this article is to persuade the readers that the project is beneficial for Nepal and persuaded the Nepal Government to pass it by accepting the project officially. The title of the article itself is framed in such a way that it is glorifying the grace of the project by proving it as one of the best development models without any visible flaws. In a sense, it has also logically appealed the readers by making some rational claims like: "Country ownership means that it is not the US government or MCC staff who are completing the project, but rather staff employed by the government of Nepal and Nepal takes the lead role in every phase of the project" (5). But it had not mentioned about the terms and conditions that Nepal need to adhere while exercising a level of freedom while implementing the project.

Kofroth uses the complex rhetorical strategies, including the Burkean scene-act ratio to achieve a specific goal. He has created a good narrative about the US-Nepal relation that is meant to not only engage the readers to listen to him, but also he is able to persuade his audience into believing that everything the US does of Nepal is motivated for the friendly purpose. He rhetorically attempts to convince his audience to become aware of the Nepal-US relation by inviting them to participate in a larger bi-lateral relationship story as "the ties that our two countries have built over our 72 years of friendship. Like all relationships, Nepal and the US continue to learn from and support one another even when challenges emerge" (5). The author has argued that it is also important to note that the agreement was signed before the Indo-Pacific Strategy was launched "like all US development assistance in Nepal, seeks to support Nepal's growth as a free, open, and secure society; the compact shares the US's vision for the IndoPacific region" (5). This article was published when the political debate regarding the Indo-pacific strategy was the burning issue (which denotes the scene) and by writing this article (which denotes the act), the author is trying to create a discourse in favour of the project by making it as an opinion to influence the masses.

Kofroth's op-ed article is also written on the basis of Aristotle's logos and pathos in which the author has tried to give various reasons to prove the fact that the US-Nepal relationship is friendly. The article is indirectly trying to narrate the value of the project for Nepal and it is also appealing the Nepal Government to ease the administrative barriers to approve the project through the parliament. So, what is important here is the appeal with a logical reason. The project is in a pre-implementation period as the government must meet a set of conditions to complete the agreement on a strict five-year clock. The MCC-Nepal and the Nepal Government continue to make progress, but in some cases, progress has been slower than desired or expected. A current example is the parliamentary ratification when the government did not achieve it on time. For the project to move forward, the approval by the majority in the parliament must be expeditiously completed.

Kofroth's article mentions many evidences to support the argument, which aims to make the Nepal Government to approve the project. In this case, the author writes, "As a result of its strong policy performance, Nepal was selected as eligible to develop a compact in December 2014. And, in September 2017, Nepal signed the \$500 million MCC Compact" (5). It has emphasized on the logical point that Nepal as a country itself has signed the agreement by going through various stages to reach this goal.

The author has also employed some strategies like pathos to show the collective benefit of the project for both Nepal and the US. Using the words like 'we' and 'our'; the author is trying to make an emotional appeal. At the end of the article, the author 
The Op-ed Articles on the Millennium Challenge Corporation (MCC) Project 59

mentions: "The second crucial attribute offered by the compact is transparency-MCC and US standards for open government and transparency that are foundations of our own democracy" (5). Kofroth even linked the project with collective democracy by using the expression 'our democracy' as if the US Government's initiation is the leap to maintain democracy in Nepal. Then, the author ends the article by congratulating Nepal for passing the project and calls for the cooperation of all governmental officials and parliamentarians to cooperate with the US Government in making the project successful. This indicates that the use of ethos as he has used his credibility as the resident country director is to make promises and lure the Nepali stakeholders by showing the benefits of the project. Thus, the article has used all three modes of persuasion: ethos, logos and pathos to convince the readers to support the project in Nepal.

Jagadish Prasad Bista, an academician and researcher, has given a very persuasive argument in favour of the MCC project through his article "The Nitty-Gritty of the MCC Compact," which begins with the controversies surrounding the project and finally gives a very valid reason on why Nepal needs to support the project on getting the financial investment. This approach can best be analyzed from the lens of persuasion by borrowing some of the conceptual insights from the new rhetoric. Perelman has defined the new rhetoric as "the study of the discursive techniques allowing us to induce or to increase the mind's adherence to the theses presented for its assent" (4). He holds the belief that when disputable premises or instances, or assumptions erupt among people, the possible way to reach the desired result would be to begin from generally accepted opinions about the problems put forth. However, the aim of soliciting adherence from the audiences is gradual as well as a relative process. It is gradual because different people's adherence to the project might vary in intensity and relative since what may solicit compliance from one person may not necessarily solicit from the other. The approval of the proposal varies because the value judgment of the evaluating audiences differs from individual to individual.

While analyzing the theme of Bist's article, it is relevant to discuss Burke's idea who argued that "the 'scene' in the sense of setting, or background, and 'act' in the sense of action, one could say that the scene contains the act. Using 'agents' in the sense of actors, one could say that "the scene contains the agents" (3). The scene described in the article is the context of foreign direct investment, which sets the background that Nepal is in need of fund and then the author cleverly presents the idea of accepting the fund offered under the project. The article was published at the time when Nepal was on the edge of receiving the foreign direct investment (FDI) from many countries for development works. The author used that content as best scene to prove his point via an agency of popular news outlet like The Kathmandu Post. Though the article is trying to balance against its argument as it has clarified some of the doubts regarding the controversies surrounding the project, it is directly pushing the readers to support its argument. Under the sub-topic of "Should Nepal Sign the Pact," it mentions:

Though some of the clauses and articles have garnered a great deal of attention from different stakeholders, the economic benefits cannot be overlooked. The MCC Compact has come at a time when the country is striving to woo foreign investment. The country seriously needs foreign investment in electricity transmission and road connectivity. MCC is not only about benefitting in the areas of high voltage electricity supply and road connectivity, but also about informing the rest of the world that Nepal is a place to invest. MCC minutely examines economic freedom, governance, investment security and other issues that are of great concern to foreign investors. (4) 
The Op-ed Articles on the Millennium Challenge Corporation (MCC) Project 60

In the above argument, the author has used logos as the dominant mode of persuasion as it has linked the project with economic freedom, investment security and the way to please other foreign investors to invest in Nepal. It further argues that many economists are supporting the grant. Here, the article gives an evidence to support its claim, stating that "the economic benefits of ratifying the MCC Compact clearly outweigh the costs" (4), but it does not discuss about the other side of the grant, which is the security issue for Nepal.

As Aristotle has claimed "Persuasion is clearly a sort of demonstration, since we are most fully persuaded when we consider a thing to have been demonstrated. For argument based on knowledge implies instruction" (4). Based on the argument as put forward by Aristotle, Bista has tried to instruct the readers to support the project by establishing very convincing knowledge of the link of the project with the impact that it would have in the future FDI grants and why should Nepal accept the project for attracting other international investors. In the same regard, Aristotle has argued:

We must be able to employ persuasion, just as strict reasoning can be employed, on opposite sides of a question, not in order that we may in practice employ it in both ways (for we must not make people believe what is wrong), but in order that we may see clearly what the facts are, and that, if another man argues unfairly, we on our part may be able to confute. (7)

The author has discussed about another side of the debate in the beginning of the article as he writes, "arguments have also been extended that MCC is part of a military stunt which the US Embassy has firmly denied. But the MCC Compact itself contains no military component" (6). However, the larger part of the article is directed to narrate the benefits of the project and the opposing arguments are not clearly discussed to satisfy or convince the critical readers. The ordinary readers may not identify this argument, which has strategically demonstrated the good side of the project, but the critical readers can recognize the rhetorical techniques used in the article. While borrowing the statement of Aristotle, the things that are "true and things that are better are, by their nature, practically always easier to prove and easier to believe in" (6). If the project had all good aspects and if it was not influenced by any military or security agenda, then the author could have proved this fact very easily.

The process of identifying the ratios and relationship between separate elements of the pentad within a piece of writing is a useful way to understand how the pentad is functioning as a rhetorical tool to pursue the speaker's goals (Dunn 6). As noted in the analysis of the previous articles, some texts may indicate toward more than one ratio of pentad, while in others, a particular ratio may transform over the course of the text. Thus, the article entitled "Nepal Must Not Lose $\$ 500 \mathrm{~m}$ MCC Grant" by Pallav Bhusal, published in The Rising Nepal can be analyzed within the same conceptual frame. This article is the best example of more than one ratio, which has focused on the good aspects of the project and has tried to convince the mass to support it. The different ratios that the author has employed can be a valuable insight into both how the author wants the Nepali public to see the grant and the rhetorical strategies that he uses to motivate his audience to accept his viewpoint. The purpose-agent ratio dominates the first strand of Bhusal's argument consistently, while discussing the energy benefit for Nepal as the US Government is investing in electricity through the grant. In addition, the author also mentions that other 50 nations have already approved the grant to prove the credibility of the project. For instance, the article mentions:

The US government's Millennium Challenge Corporation (MCC) has provided $\$ 500$ million in grants to Nepal for building electricity transmission lines and road. It is the biggest grant assistance the US approved for Nepal, with the latter 
The Op-ed Articles on the Millennium Challenge Corporation (MCC) Project 61

chipping in $\$ 130$ million to boost the MCC project. The MCC has offered grants to over 50 developing countries. MCC's Nepal Compact mainly seeks to increase the availability of electricity and lower the cost of transportation, thereby helping the government better deliver critical services to the people, ease the movement of goods and open up new opportunities to investors. (5) Here, it is very clear that the purpose of the author is to push the good aspect of the MCC project for the public good. Anyone can trace the purpose-agency ratio explicitly visible in the article. The Rising Nepal being a governmental newspaper speaks the language of government and the time when this article was published both then Prime Minister KP Oli and Foreign Minister Pradeep Gyawali were in favour of the project. In December 2019, then Minister Gyawali has said "The government has decided to move forward with the agreement. Therefore, the lawmakers need not to be confused about the implementation of the development project" (Bhatta, 2019). Thus, the purpose of this statement was to support the decision of the government and the role of agency is fulfilled by the government newspaper The Rising Nepal and the author Bhusal too is a journalist of the same newspaper. In other words, the purpose is in favour of the government and the agency is also controlled by the government, so the purpose-agency ratio dominates this article. Similarly, there are also some traces of scene-agent ratio in the article as the publication happened at the time when the governmental stakeholders were openly defending and supporting the project. For example, in 2019, then Prime Minister Oli was openly appealing the people to support the project saying, "The projects have not come through the backdoor. They have come through the main gate. The projects will be built be it by MCC, or anyone else, or by the government itself" (Setopati). This article was published after the scenario when the then prime minister of Nepal verbally endorsed the project and The Rising Nepal as governmental newspaper acted as the agent to support the statement of the prime minister. In this way, the sceneagent ration in the article is the opinion that has pushed the viewpoint through one of the trusted newspapers of Nepal.

In another article "What Ails Our Diplomacy?" Niranjan Mani Dixit has tried to explore the possible negative consequence of approving the project by proving it as a failure of Nepali diplomacy and comparing it with other anti-national treaties signed by Nepal in the past:

In our case, duty bearers in the ruling party and bureaucracy initially failed to read thoroughly and understand the MCC pact's critical terms and conditions a number of which were already inconsistent with Nepal's laws and the constitution. It has been reported that Finance Ministry in coordination with the Foreign Ministry have already signed other 14 foundational documents to that effect as green signals. Ironically, a layman's understanding also suggests that US government's grants aid agreement or any strategic treaty is not subject to omission or amendment. (5)

Here, the author has developed his opinion, using persuasion at ethical and logical level as he has mentioned that the project could just be a tip of iceberg and invite other dangerous consequences to the nation. In addition, the comparison of this project with the '1950 Indo-Nepal Treaty of Peace and Friendship,' which is considered one of the historical diplomatic blunders done by Nepal that ethically appeals the readers to cultivate a negative viewpoint regarding the project. Though the project is directly related with the US Government, the project has been compared with the international treaty signed between Nepal and India to let the Nepali readers feel the possible threat that the project can bring to the country. The author has mobilized the anti-Indian sentiment as a percussive tool to convince the readers about the negative side of the 


\section{The Op-ed Articles on the Millennium Challenge Corporation (MCC) Project 62}

project. The author has used logos as the mode of persuasion because there are many direct reasonings to oppose the project. He has used very precise arguments when he argues that the political stakeholders of Nepal have failed to understand the clauses of the project that are against the constitution of the country. However, he has not mentioned the specific clauses and reasons behind the project. He has not revealed any evidences that prove the inability of leaders to understand the clauses. Thus, it is clear that the rhetorical appeal of the article is comparatively weaker than other articles discussed in this paper. While analyzing from the theoretical lens of dramatism pentad, it can be argued that the rhetoric of the author fits more into the scene-purpose ratio as the author has focused on the context of weak diplomacy and used the case of the project as a reference to prove the inability of the political leaders by highlighting on the negative aspect of the project.

Another article "MCC in The Soup" by Uttam Maharjan has highlighted on some points against the project. His argument has pushed the readers to question some of the issues surrounding the project that actually discourage the government to endorse the project. The article has focused on the negative consequence of the project if it is passed as it is in the original form without some amendments. In other words, the article is against passing the project as the author states:

The MCC compact should have been thoroughly discussed and deliberated upon among the leaders, experts and other stakeholders before signing it in 2017. As per the report of the taskforce, the compact seems to have been signed on an adhoc basis by the government without going into details about its contents. Although the compact was signed by the Nepali Congress government, the NCP government is equally eager to endorse it at any cost. Now, the government has found it heavy going to endorse the compact as it is inasmuch as even most leaders of the ruling NCP are not in favour of endorsing the US grant in its current form. So, it behoves the government to take pragmatic decisions before accepting it. (5)

The above-mentioned statement is the conclusion of Maharaja's view on the project, which has directly encouraged the readers to think before supporting the project. To analyze the article from the pentad perspective, it is important to understand that performing a pentadic analysis is not an exercise in discovering the absolute truth. But Burke's model intends to reveal the complex ways in which humans symbolically interact through the use of language and rhetoric as C. Fox argued that rather than reducing interactions to a single reality, the pentad "provides us with constructive possibilities for uncovering multiple truths" (370). In this regard, the scene-purpose ratio is more dominant in this article because as mentioned above, it is published after the task force submitted its report to then Prime Minister Oli and Co-Chair Pushpa Kamal Dahal 'Prachanda'. In this case, the scene is that the report was against passing the project as it is and the stakeholders were demanding for its amendment. Therefore, in line with the rhetorical situation, the direct purpose of this article is to make the public aware about the negative consequence of passing the project and the implicit purpose is to discourage the public from supporting the project.

\section{Conclusion}

From the discussion of the above-mentioned op-ed articles it can be concluded that the pentad itself is not enough to explain a rhetorical situation. The real power of the pentadic elements lies in their relationships with one another. Each element is linked to the other in which understanding of one term is inevitably knotted to understanding of all the other terms. The link between the elements is called pentadic ratios that offer new 
ways of viewing the situation through the rhetorical filters. Therefore, Burke has described ten ratios (scene-act, scene-agent, scene-agency, scene-purpose, act-purpose, act-agent, act-agency, agent-purpose, agent-agency and agency-purpose), which help establish what factors are controlling the rhetorical situation. During the analysis, this paper discovered the most important dimension of rhetoric in writing by studying the oped articles from each ratio and by identifying how the two terms have influenced or determined each other to make it a rhetorical argument. The combined use of Burke's 'dramatism pentad' and Aristotle's 'modes for persuasion' helped in identifying various rhetorical techniques used in the op-ed articles that were employed to support and oppose the MCC project as per the motive of the respective authors. This paper has not only analyzed the rhetorical techniques, but it has also tried to study the purpose behind using a rhetorical approach to meet a particular objective, using the dramatistic pentad.

\section{Works Cited}

Aristotle, W R. Roberts, Ingram Bywater, Friedrich Solmsen. Rhetoric. Modern Library, 1954.

Aristotle. On Rhetoric: A Theory of Civic Discourse. Translated by George A. Kennedy. Oxford UP, 1991.

Bhatta, Subin. "No Dilemma on MCC Ratification: Gyawali." GorakhaPatra, 26 December 2019, https://risingnepaldaily.com/main-news/no-dilemma-on-mccratification-gyawali. Accessed 23 Nov. 2021.

Bhusal, Pallav. "Nepal Must Not Lose \$500m MCC Grant." GorakhaPatra, 3 January 2020, https://risingnepaldaily.com/detour/nepal-must-not-lose-500m-mcc-grant. Accessed 23 Nov. 2021.

Bista, Jagadish Prasad. "Opinion: The Nitty-Gritty of the MCC Compact." The Kathmandu Post, 20 February 2020. The Kathmandu Post (online), https://kathmandupost.com/columns/2020/02/20/the-nitty-gritty-of-the-mcccompact. Accessed 23 Nov. 2021.

Blakesley, David. The Terministic Screen: Rhetorical Perspectives on Film. Southern Illinois UP, 2007.

Burke, Kenneth. "Questions and Answers about the Pentad." College Composition and Communication, vol. 29, no. 4, 1978, pp. 330-335. JSTOR, www.jstor.org/stable/357013. Accessed 1 June 2020.

Burke, Kenneth. A Grammar of Motives. Berkeley: U of California P, 1969.

Dixit, Nirajan Mani. "My Republica-The New York Times Partner, Latest News of Nepal in English, Latest News Articles." My Republica, 15 March 2020, https://myrepublica.nagariknetwork.com/news/author/3974.\%20Accessed\%201 1\%20December\%202020. Accessed 11 December 2020

Dunn, R. Chase. "'The Future is in Good Hands': A Pentadic Analysis of President Barack Obama's Farewell Address." Kaleidoscope: A Graduate Journal of Qualitative Communication Research, vol. 17, no. 1, 2018, pp. 73-90.

Fox, C. "Beyond the 'Tyranny of the Real': Revisiting Burke's Pentad as Research Method for Professional Communication." Technical Communication Quarterly, vol. 11, no. 4, 2002, pp. 365-388. Accessed 7 December 2020

House of Representatives, Nepal. Millennium Challenge Compact between the United States of America Acting through the Millennium Challenge Corporation and the Federal Democratic Republic of Nepal Acting through the Ministry of Finance, 2017, https://hr.parliament.gov.np/uploads/attachment/ns1_zpda2uw3x2odp.pdf. Accessed 12 Oct. 2021. 
The Op-ed Articles on the Millennium Challenge Corporation (MCC) Project 64

Kneupper, Charles W. "The Relation of Agency to Act in Dramatism: A Comment on 'Burke's Act."' College English, vol. 47, no. 3, 1985, pp. 305-308. JSTOR, www.jstor.org/stable/376784.

Kofroth, Troy. "Opinion: A Model for Transparent Development Projects." The Kathmandu Post, 18 November 2019. The Kathmandu Post (online), https://kathmandupost.com/columns/2019/11/18/a-model-for-transparentdevelopment-projects.

Leith, Sam. Words like Loaded Pistols: Rhetoric from Aristotle to Obama. Basic Books, 2016.

McNally, James Richard. "Toward a Definition of Rhetoric." Philosophy \& Rhetoric, vol. 3, no. 2, 1970, pp. 71-81. JSTOR, www.jstor.org/stable/40236708.

McQuail, Denis. "Sociology of Mass Communication." Annual Review of Sociology, vol. 11, 1985, pp. 93-111. JSTOR, www.jstor.org/stable/2083287.

Overington, Michael A. "Kenneth Burke and the Method of Dramatism." Tehor Soc, vol. 4, 1977, pp 131-156. https://doi.org/10.1007/BF00209747.

Perelman, Chaim, and Lucie Olbrechts-Tyteca. The New Rhetoric: A Treatise on Argumentation. U of Notre Dame P, 1969.

Singh, Prashaant. "Debunking the Nonsense on MCC." My Republica, 7 January 2020. My Republica (online), myrepublica.nagariknetwork.com/news/debunking-thenonsense-on-mcc/.

Xiaoyan, Liu and Nancy Lynch Street. "The Analysis of Senator Barack Obama's Speech on Race by Kenneth Burke's Idea of Dramatism." The International Journal of the Humanities: Annual Review, vol 7, no. 1, 2009, pp. 83-92. Common Ground Research Networks, https://doi.org/10.18848/1447-9508/cgp/v07i01/42578

\section{To cite this article [MLA style]:}

Poudyal, Biranchi. "The Op-ed Articles on the Millennium Challenge Corporation (MCC) Project: A Rhetorical Analysis." SCHOLARS: Journal of Arts \& Humanities, vol. 4, no. 1, February 2022, pp. 53-64. NepJOL, doi:10.3126/sjah.v4i1.43055. 